\title{
Prescribing of $\beta$-adrenoceptor antagonists in asthma: an observational study
}

\author{
Daniel R Morales, ${ }^{1}$ Bruce Guthrie, ${ }^{2}$ Brian J Lipworth, ${ }^{3}$ Peter T Donnan, ${ }^{4}$ \\ Cathy Jackson ${ }^{1}$
}

${ }^{1}$ School of Medicine, University of St Andrews, Fife, UK ${ }^{2}$ Quality \& Safety Improvement Research Group, Division of Clinical \& Population Sciences \& Education, University of Dundee, Dundee, UK

${ }^{3}$ Asthma \& Allergy Research Group, University of Dundee, Dundee, UK

${ }^{4}$ Dundee Epidemiology \& Biostatistics Unit, Division of Clinical \& Population Science \& Education, University of Dundee, Dundee, UK

\section{Correspondence to}

Professor Cathy Jackson, School of Medicine, Medical \& Biological Sciences Building, North Haugh, University of St Andrews, St Andrews, Fife KY16 9TF, UK:

c.jackson@chs.dundee.ac.uk

Received 21 February 2011 Accepted 22 February 2011 Published Online First 1 April 2011

\section{ABSTRACT}

Background $\beta$-Antagonists have recently been proposed for the treatment of chronic asthma; however, concerns regarding risk of acute bronchoconstriction in clinical trials remain.

Objective To determine the frequency of oral $\beta$-blocker prescribing in patients with asthma and associations with severe asthma exacerbations requiring oral steroids in patients with active asthma defined by prior asthma-related medication use.

Methods Patients with asthma registered on 31 March 2007 and all asthma-related medications from the preceding 2 years were identified from anonymised clinical data from one-third of Scottish general practices. The main outcome measure was the relative incidence of active asthma patients receiving oral steroids following a new oral $\beta$-antagonist prescription.

Results Of the 53994 adult patients identified with asthma 1527 (2.8\%; 95\% Cl 2.69\% to $2.97 \%$ ) patients were prescribed an oral $\beta$-antagonist of which 441 (28.9\%, 95\% Cl $26.7 \%$ to $31.2 \%$ ) had active asthma and received a new $\beta$-blocker prescription. The average number of patients prescribed rescue steroids at baseline in 367 patients with sufficient follow-up was 3.4 (0.9\%) patients every 2 weeks. Rescue steroids were prescribed to $3(0.8 \%)$ patients in the first 2 weeks and to $3(0.8 \%)$ patients in the second 2 weeks following the new oral $\beta$-antagonist (incidence rate ratio (IRR) $0.87,95 \% \mathrm{Cl} 0.25$ to 2.99 and IRR $0.89,95 \% \mathrm{Cl} 0.26$ to 2.97 , respectively). No significant difference was found following stratification for $\beta$-antagonist selectivity.

Conclusion These results suggest that prescribing new oral $\beta$-blockers for the purpose of investigating potentially beneficial effects of chronic treatment would not lead to large increases in patients treated with oral steroids acutely in general practice.

\section{INTRODUCTION}

Asthma is a common chronic disease, with a high prevalence rate reported in Scotland (18.4\%), compared with England (15.3\%), New Zealand (15.1\%), Australia (14.7\%) and Canada (14.1\%). ${ }^{1}$ Short-acting inhaled $\beta 2$-agonists (SABAs) have a longstanding central role as the primary treatment for acute relief of asthma symptoms. More recently long-acting $\beta 2$-agonists (LABAs) have also been recommended for use as add on controller therapy to inhaled corticosteroids (ICS) in patients requiring regular reliever therapy at step three of the guidelines. ${ }^{2}{ }^{3}$ Recent guidance from the Food and Drug Administration (FDA) highlighted concerns regarding the long-term safety of LABAs and has led to a re-appraisal of their role as add on

\section{Key messages}

What is the key question?

- Are patients with asthma prescribed oral $\beta$-blocker therapy despite safety concerns?

What is the bottom line?

- The incidence of oral $\beta$-blocker prescribing to patients with asthma was 6.4 per 1000 asthma patients per year with an annual prevalence of $2.2 \%$.

\section{Why read on?}

- We found that large increases in the number of patients prescribed rescue oral steroids did not occur following new oral $\beta$-blocker therapy in active asthma.

controller therapy to inhaled steroids. ${ }^{4}$ In contrast, $\beta$-adrenergic antagonists or $\beta$-blockers are typically contraindicated in asthma due to the potential to induce opposing effects, namely acute bronchoconstriction. 56

The effects of $\beta 2$-adrenoceptor antagonists has recently received close attention as studies have suggested that chronic treatment with the nonselective $\beta 2$-adrenoceptor antagonist nadolol may lead to reductions in airway hyper-responsiveness, inflammation, and upregulation of $\beta 2$-adrenoceptors in the asthmatic mouse model. ${ }^{7-9}$ In a subsequent open label study involving steroid-naïve patients with mild asthma, chronic dosing with the nonselective $\beta$-blocker nadolol over 12 weeks caused a significant reduction in airway hyper-responsiveness to methacholine challenge along with a small residual fall in forced expiratory volume in $1 \mathrm{~s}\left(\mathrm{FEV}_{1}\right)$ after an initial greater fall on first dose exposure. ${ }^{10}$ So-called cardioselective $\beta$-blockers, such as atenolol and bisoprolol, demonstrate greater affinities for $\beta 1$ - than $\beta 2$-adrenoceptors, although the ratios of $\beta 1$ : $\beta 2$ antagonism show marked variation between different agents. ${ }^{11}$ The effects of cardioselective $\beta$-blocker exposure in those with mild to moderate asthma have been investigated using a meta-analysis of randomised, blinded placebo-controlled trials. ${ }^{12}$ Single dosing with cardioselective $\beta$-blockers produced a significant reduction in $\mathrm{FEV}_{1}$ of $7.46 \%$ without affecting symptoms, while $\mathrm{FEV}_{1}$ was not significantly reduced by chronic dosing. In addition, a significant increase in subsequent $\beta$-agonist response was seen upon chronic dosing, indicating that $\beta 2$-receptor upregulation may occur. This could explain how the beneficial effect of $\beta$-blockers in 
asthma may only be seen upon chronic dosing, as is the case with heart failure.

In a Commentary on the therapeutic potential of $\beta$-blockers for asthma, the issue was raised that it would be important to evaluate the potential adverse effects of $\beta$-blockers on exacerbations of asthma from real-life prescribing data in patients who were already co-prescribed $\beta$-agonists and antagonists. ${ }^{13}$ Such prescribing is not uncommon, with a previous analysis of prescriptions issued in primary care in the Tayside region of Scotland demonstrating that $\sim 1.7 \%$ of patients receiving a $\beta$-blocker prescription had received a $\beta 2$-agonist in the preceding 30 days. ${ }^{14}$ We wished to know how patients with asthma tolerated oral cardioselective and non-selective $\beta$-blockers in real life, especially in terms of precipitating severe exacerbations, in order to inform the likely risk of performing further prospective randomised controlled trials to explore the therapeutic potential of $\beta$-blockers in asthma.

The aim of the present study was to examine the prevalence of oral $\beta$-blocker prescribing in a large cohort of people with asthma, and to determine whether the initial oral $\beta$-blocker prescription was associated with large increases in the number of patients receiving treatment with oral steroids for severe exacerbations of asthma.

\section{METHODS}

Anonymised clinical data were obtained from the Primary Care Clinical Informatics Unit at the University of Aberdeen. The data extract was from 310 of the 1031 Scottish general practices with 1.76 million registered patients who are representative of the wider population in terms of age, sex and deprivation. ${ }^{15}$ Analysis of anonymised clinical data conformed to the Primary Care Clinical Informatics Unit research governance process.

Data were extracted for all patients with an asthma Read Code permanently registered on 31 March 2007 and included patient age, sex, smoking status, additional diagnosis of chronic obstructive pulmonary disease (COPD) and all asthma-related medications prescribed in the previous 2 years including SABAs, LABAs, ICS, leukotriene antagonists, theophyllines, oral steroids and $\beta$-blockers.

\section{Asthma cases}

For patients aged $18-40$, cases of asthma were defined as adult patients with a Read Code for asthma and no Read Code for COPD, defined by the Quality and Outcomes Framework (QOF) business rules as part of the new General Medical Services (GMS) contract for general practice in the UK. To ensure exclusion of patients with undiagnosed COPD, patients aged $>40$ were included only if they were additionally recorded as 'never smoked' according to their QOF Read Code for smoking status.

\section{Asthma exacerbation}

The main outcome measure was the incidence of patients receiving treatment with oral steroids in consecutive 2 -weekly intervals. Due to the variation in oral steroid use and potential for confounding, analysis was performed using two separate oral steroid outcome measures. The main outcome measure was the incidence of patients receiving rescue oral steroid, defined as a total prednisolone prescription dose of $\leq 350 \mathrm{mg}$ and a prescription duration of $<2$ weeks calculated using quantity, dose and frequency information on the prescription. The secondary outcome measure was the incidence of patients prescribed any oral steroid.

\section{New $\boldsymbol{\beta}$-blocker prescriptions in patients with active asthma}

A new oral $\beta$-blocker prescription was defined as the first prescription for an oral $\beta$-blocker with a pre-exposure period of $\geq 84$ days. Active asthma was defined using prescriptions of asthma-related medication occurring between 1 January 2005 and the date of the new $\beta$-blocker prescription, including prescriptions of SABAs, LABAs, ICS, combination inhalers (LABA/ICS), theophylline and leukotriene antagonists. To determine the effects on oral steroid prescribing, patients were required to have a follow-up period of at least 84 days after a new oral $\beta$-blocker prescription.

\section{British Thoracic Society/Scottish Intercollegiate Guideline Network (BTS) treatment step}

The BTS guidelines for the management of asthma are UK national level guidelines aimed to help both primary and secondary care clinicians in the management of asthma. ${ }^{2}$ They advocate a stepwise approach to the treatment of asthma in the UK. The BTS treatment step was calculated using prescriptions issued in the 84 days prior to the new $\beta$-blocker. These were defined as step one (SABA use only), step two (ICS \pm SABA use only), step three (step two including add-on therapy with a LABA, leukotriene antagonist or theophylline), and step four (step three with high-dose ICS or with the addition of a fourth drug). High-dose ICS was defined as an inhaled ICS dose of $\geq 1000 \mu \mathrm{g}$ beclomethasone equivalent per day.

\section{Analysis}

Binary logistic regression was performed using simple contrasting in order to determine the effects of $\beta$-antagonist prescribing between gender and age. Poisson regression with a generalised estimating equation (GEE) approach was used to determine incidence rate ratios (IRRs) of patients prescribed oral steroids between time periods around the first $\beta$-blocker prescription only. A model-based estimator using an autoregressive (AR1) correlation matrix was applied. The significance threshold was $5 \%$ and

Table 1 Distribution of $\beta$-blocker exposure by age, gender and selectivity in all asthma patients

\begin{tabular}{lcccl}
\hline Variable & Cardioselective, $\mathbf{n}(\%)$ & Non-selective, $\mathbf{n}(\%)$ & Any $\boldsymbol{\beta}$-blocker $(\%)$ & $\mathbf{0 R}$ for any $\boldsymbol{\beta}$-blocker $\mathbf{( 9 5 \%} \mathbf{~ C l )}$ \\
\hline Age group & & & & \\
$\quad<40$ & $90(9.3)$ & $339(57.6)$ & $418(27.4)$ & 1.00 \\
$40-49$ & $79(8.3)$ & $95(16.1)$ & $173(11.3)$ & $1.31(1.10$ to 1.57$)$ \\
$50-59$ & $169(17.4)$ & $59(10.0)$ & $221(14.5)$ & $2.40(2.03$ to 2.83$)$ \\
$60-69$ & $259(26.7)$ & $44(7.5)$ & $297(19.4)$ & $4.29(3.69$ to 5.00$)$ \\
$\geq 70$ & $373(38.5)$ & $52(8.8)$ & $418(27.4)$ & $5.53(4.81$ to 6.35$)$ \\
Total & $970(100.0)$ & $589(100.0)$ & $1527(100.0)$ & \\
Gender & & & & \\
Male & $345(35.6)$ & $142(24.1)$ & $478(31.3)$ & 1.00 \\
Female & $625(64.4)$ & $447(75.9)$ & $1049(68.7)$ & $1.53(1.37$ to 1.71$)$ \\
Total & $970(100.0)$ & $589(100.0)$ & $1527(100.0)$ & \\
\hline
\end{tabular}


Table 2 Dose of oral $\beta$-blockers prescribed to defined asthma patients

\begin{tabular}{|c|c|c|c|}
\hline $\begin{array}{l}\beta \text {-Blocker } \\
\text { prescription }\end{array}$ & $\begin{array}{l}\text { Frequency } \\
(\%)\end{array}$ & $\begin{array}{l}\text { Daily prescription } \\
\text { dose range }\end{array}$ & $\begin{array}{l}\text { Prescription mean } \\
\text { daily dose }(95 \% \mathrm{CI})\end{array}$ \\
\hline \multicolumn{4}{|c|}{ Non-selective ( $n=589$ ) } \\
\hline Propranolol & $507(85.9)$ & $10-320 \mathrm{mg}$ & $83.6 \mathrm{mg}(80.0$ to 88.2$)$ \\
\hline Sotalol & $27(4.6)$ & $40-360 \mathrm{mg}$ & $149.3 \mathrm{mg}$ (114.3 to 184.3 ) \\
\hline Labetolol & $25(4.2)$ & $100-1200 \mathrm{mg}$ & $558.7 \mathrm{mg}$ (456.2 to 661.2 ) \\
\hline Carvedilol & $24(4.1)$ & $3.125-50 \mathrm{mg}$ & $25.3 \mathrm{mg}$ (23.4 to 27.2 ) \\
\hline Oxprenolol & $5(0.8)$ & $80-320 \mathrm{mg}$ & $176.7 \mathrm{mg}$ (49.3 to 304.1$)$ \\
\hline Timolol & $2(0.3)$ & $10 \mathrm{mg}$ & $10 \mathrm{mg}$ \\
\hline Total & $590(100.0)$ & & \\
\hline \multicolumn{4}{|c|}{ Selective $(n=970)$} \\
\hline Atenolol & $635(63.2)$ & $12.5-100 \mathrm{mg}$ & $53.0 \mathrm{mg}(51.0$ to 55.0$)$ \\
\hline Bisoprolol & $288(28.7)$ & $1.25-20 \mathrm{mg}$ & $5.8 \mathrm{mg}(5.4$ to 6.2$)$ \\
\hline Metoprolol & $58(5.8)$ & $25-400 \mathrm{mg}$ & $93.5 \mathrm{mg}$ (74.9 to 112.1$)$ \\
\hline Nebivolol & $14(1.4)$ & $5.0-10 \mathrm{mg}$ & $5.8 \mathrm{mg}(4.5$ to 7.1$)$ \\
\hline Celiprolol & $9(0.9)$ & $100-400 \mathrm{mg}$ & $205.4 \mathrm{mg}$ (136.0 to 274.8 ) \\
\hline Acebutolol & $1(0.1)$ & $200 \mathrm{mg}$ & $200 \mathrm{mg}$ \\
\hline Total & $1005(100.0)$ & & \\
\hline
\end{tabular}

analysis was performed in SPSS version 17.0. The model was inspected for overdispersion by assessing the ratio of model $\chi^{2}$ to degrees of freedom and adjusted for BTS treatment step severity and season at the time of $\beta$-blocker initiation. The immediate 2 week pre-exposure period (days -14 to -1 ) was excluded from the analysis to account for event-dependent exposures. In this regard, patients receiving treatment for an exacerbation of asthma are less likely to be prescribed a $\beta$-blocker at the same time and would result in an exaggerated relative incidence.

\section{RESULTS}

A total of 53944 adult patients with asthma were identified using our definition, of which 1527 patients $(2.8 \%$, 95\% CI $2.69 \%$ to $2.97 \%$ ) were issued a total of 12880 oral $\beta$-blocker prescriptions. Of the 1527 patients prescribed an oral $\beta$-blocker,
589 patients (38.6\%, 95\% CI $36.2 \%$ to $41.0 \%$ ) received an average of 5.1 prescriptions (95\% CI 4.6 to 5.6) for non-selective $\beta$-blockers compared with 970 patients $(63.5 \%, 95 \%$ CI $61.1 \%$ to $65.9 \%$ ) who received an average of 10.2 prescriptions (95\% CI 9.7 to 10.6) for cardioselective $\beta$-blockers, which accounted for 9874 $(76.7 \%)$ of all prescriptions issued.

Both age and gender had significant impacts on oral $\beta$-blocker prescribing in patients with asthma. The majority of patients prescribed a non-selective $\beta$-blocker (57.6\%) were under the age of 40 , while the majority of patients prescribed cardioselective $\beta$-blockers $(90.7 \%)$ were $\geq 40$ years of age. The overall odds of being prescribed any class of $\beta$-blocker increased incrementally with age (table 1).

Of the 970 patients prescribed cardioselective $\beta$-blockers, the most commonly prescribed drugs were atenolol (63.2\%) and bisoprolol (28.7\%), with a mean daily dose of $53.0 \mathrm{mg}$ for atenolol (95\% CI 51.0 to $55.0 \mathrm{mg}$ ) and $5.8 \mathrm{mg}$ for bisoprolol (95\% CI 5.4 to $6.2 \mathrm{mg}$ ) (table 2). Of the 589 patients prescribed non-selective $\beta$-blockers, the most commonly prescribed drug was propranolol (85.9\%), with a mean daily dose of $83.6 \mathrm{mg}$ (95\% CI 80.0 to $88.2 \mathrm{mg}$ ). Of the 1527 patients prescribed an oral $\beta$-blocker, 1170 patients $(76.6 \%)$ received more than one $\beta$-blocker prescription (figure 1 ). The annual prevalence of oral $\beta$-blocker prescribing in patients with asthma was $2.2 \%$ (95\% CI $2.1 \%$ to $2.3 \%)$.

\section{Oral steroid prescribing in patients with active asthma and $\boldsymbol{\beta}$-blockers}

Of the 1527 patients prescribed $\beta$-blockers, 695 patients received a new $\beta$-blocker, with an incidence of new oral $\beta$-blocker prescribing of 6.4 per 1000 asthma patients per year. The severity of asthma was defined for 599 patients, of whom 376 patients $(62.8 \%)$ received prescriptions for SABAs and 274 patients $(45.7 \%)$ prescriptions for ICS before the new $\beta$-blocker (table 3 ). In total, $36.0 \%$ of all asthma patients were at BTS

\section{Class of $\beta$ Blocker}

prescriptions received by all asthma patients according to class of $\beta$-blocker $(n=1527)$. Patients receiving nonselective $\beta$-blockers are shown by white histograms and cardioselective $\beta$-blockers are shown by shaded histograms. The majority of patients received more than one $\beta$-blocker prescription.

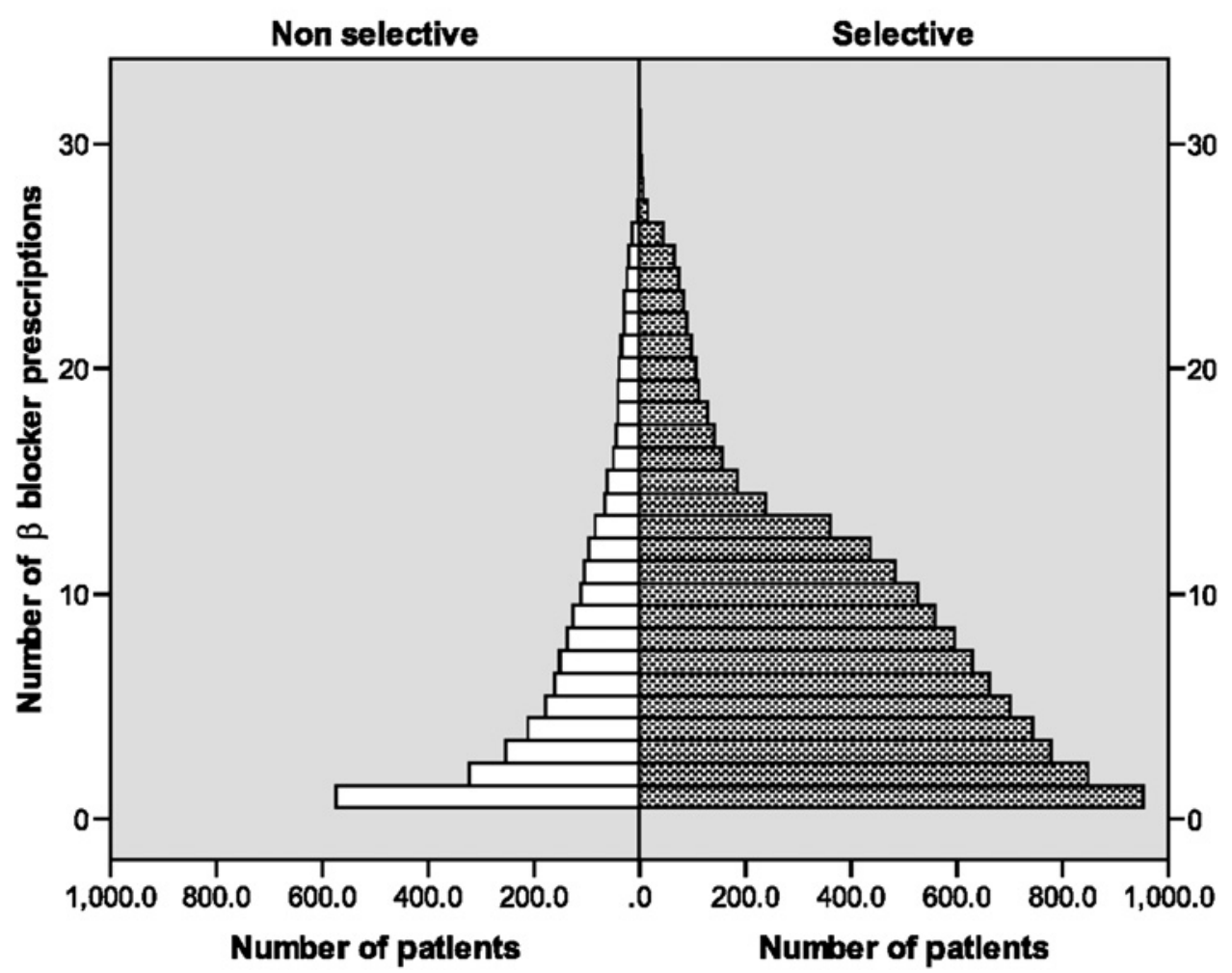


Table 3 Number of asthma patients receiving different types of asthma medication before the new oral $\beta$-blocker $(\mathrm{n}=599)$

\begin{tabular}{lc}
\hline Medication & $\begin{array}{c}\text { No. of patients receiving } \\
\text { medications }(\%)\end{array}$ \\
\hline SABA & $376(62.8)$ \\
LABA & $44(7.3)$ \\
ICS & $274(45.7)$ \\
LABA/ICS & $70(11.7)$ \\
LKT & $18(3.0)$ \\
THEO & $4(0.7)$ \\
\hline
\end{tabular}

ICS, inhaled corticosteroid; LABA, long-acting $\beta 2$-agonist; LKT, leukotriene antagonist; SABA, short-acting $\beta 2$-agonist; THEO, theophylline.

treatment step two or greater compared with $49.0 \%$ of patients with active asthma of which a total of 441 patients were identified (table 4).

Of these 441 patients with active asthma, 367 patients (83.2\%) had follow-up of at least 84 days. The number of patients treated with rescue oral steroids per 2 weeks were 3.4 patients $(0.9 \%)$ for baseline, three patients (0.8\%, IRR $0.87,95 \%$ CI 0.25 to 2.99$)$ for the first 2 weeks, three patients $(0.8 \%$, IRR $0.89,95 \%$ CI 0.26 to 2.97) for weeks $2-4$ and 2.8 patients ( $0.8 \%$, IRR $0.80,95 \%$ CI 0.39 to 1.64) for weeks $4-8$ following the new oral $\beta$-blocker prescription. The numbers treated with any oral steroid for the equivalent time periods were 4.8 patients (1.3\%), 9 patients (2.5\%, IRR $1.86,95 \%$ CI 0.88 to 3.96$)$, 9 patients (2.5\%, IRR 1.85 , $95 \%$ CI 0.87 to 3.93 ) and 5.8 patients (1.6\%, IRR $1.19,95 \%$ CI 0.69 to 2.04$)$, respectively. Figure 2 shows the proportion of patients with active asthma requiring oral steroid therapy before and after the new oral $\beta$-blocker prescription, and no major increase in oral steroid prescribing was seen. No statistical difference was found in the proportion of patients prescribed oral steroids in the weeks following a new $\beta$-blocker prescription (table 5).

\section{DISCUSSION}

The main concern when designing studies to examine the potential therapeutic use of $\beta$-blockers in asthma remains the
Table 4 BTS treatment step for all asthma patients $(n=599)$ and active asthma patients $(n=441)$ immediately prior to the new oral $\beta$-blocker prescription

\begin{tabular}{llllll}
\hline & \multicolumn{2}{l}{$\begin{array}{l}\text { All asthma patients with } \\
\beta \text {-blockers }\end{array}$} & & \multicolumn{2}{l}{$\begin{array}{l}\text { Active asthma patients with } \\
\beta \text {-blockers }\end{array}$} \\
\cline { 2 - 3 } \cline { 5 - 6 } $\begin{array}{l}\text { BTS } \\
\text { step }\end{array}$ & $\begin{array}{l}\text { Cardioselective } \\
(\%)\end{array}$ & $\begin{array}{l}\text { Non- } \\
\text { selective } \\
(\%)\end{array}$ & & $\begin{array}{l}\text { Cardioselective } \\
(\%)\end{array}$ & $\begin{array}{l}\text { Non- } \\
\text { selective } \\
(\%)\end{array}$ \\
\hline 1 & $150(57.7)$ & $233(68.7)$ & $89(44.7)$ & $135(55.8)$ \\
2 & $69(26.5)$ & $61(18.0)$ & $69(34.7)$ & $61(25.2)$ \\
3 & $23(8.8)$ & $27(8.0)$ & & $23(11.6)$ & $27(11.2)$ \\
4 & $17(6.5)$ & $18(5.3)$ & & $17(8.5)$ & $18(7.4)$ \\
Other & $1(0.4)$ & $1(0.3)$ & & $1(0.5)$ & $1(0.4)$ \\
Total & $260(100.0)$ & $339(100.0)$ & $199(100.0)$ & $242(100.0)$ \\
\hline Other, patients with either long-acting $\beta 2$-agonist or theophylline monotherapy. \\
BTS, British Thoracic Society/Scottish Intercollegiate Guideline Network.
\end{tabular}

risk of inducing acute bronchoconstriction. It is likely that any benefit of $\beta$-blockers in asthma will only be seen upon chronic dosing, perhaps after an initial period of dose titration. Similar concerns existed for the use of $\beta$-blocker therapy in heart failure patients which can safely be initiated and is highly effective. ${ }^{16}$ The result of this population-based study showed that the annual prevalence of oral $\beta$-blocker prescribing to adult patients with asthma in Scotland was $2.2 \%$. Selective $\beta$-blockers were prescribed more often in older patients who are more likely to have compelling indications for $\beta$-blockade such as ischaemic heart disease and heart failure. Female patients were more likely to be prescribed a non-selective $\beta$-blocker than males. This may represent the increased prevalence of conditions associated with non-selective $\beta$-blocker treatment in females such as anxiety, migraine, thyrotoxicosis and pre-eclampsia. Although reasons for prescribing at the level of primary care remain heterogeneous and complex, it is possible that this observation is partly due to the exclusion of patients from our population over the age of 40 with an exposure to smoking. Misclassification of patients with COPD would increase the observed prevalence of $\beta$-blocker prescribing as current recommendations state that cardioselective $\beta$-blockers can be safely used in patients with COPD. ${ }^{17}$

Figure 2 Proportion of $\beta$-blocker naive patients with active asthma $(n=367)$ with at least 84 days follow-up receiving prescriptions of rescue oral steroids (bottom dotted line) and any oral steroid (top solid line) before and after the first $\beta$-blocker prescription (indicated by the reference line).

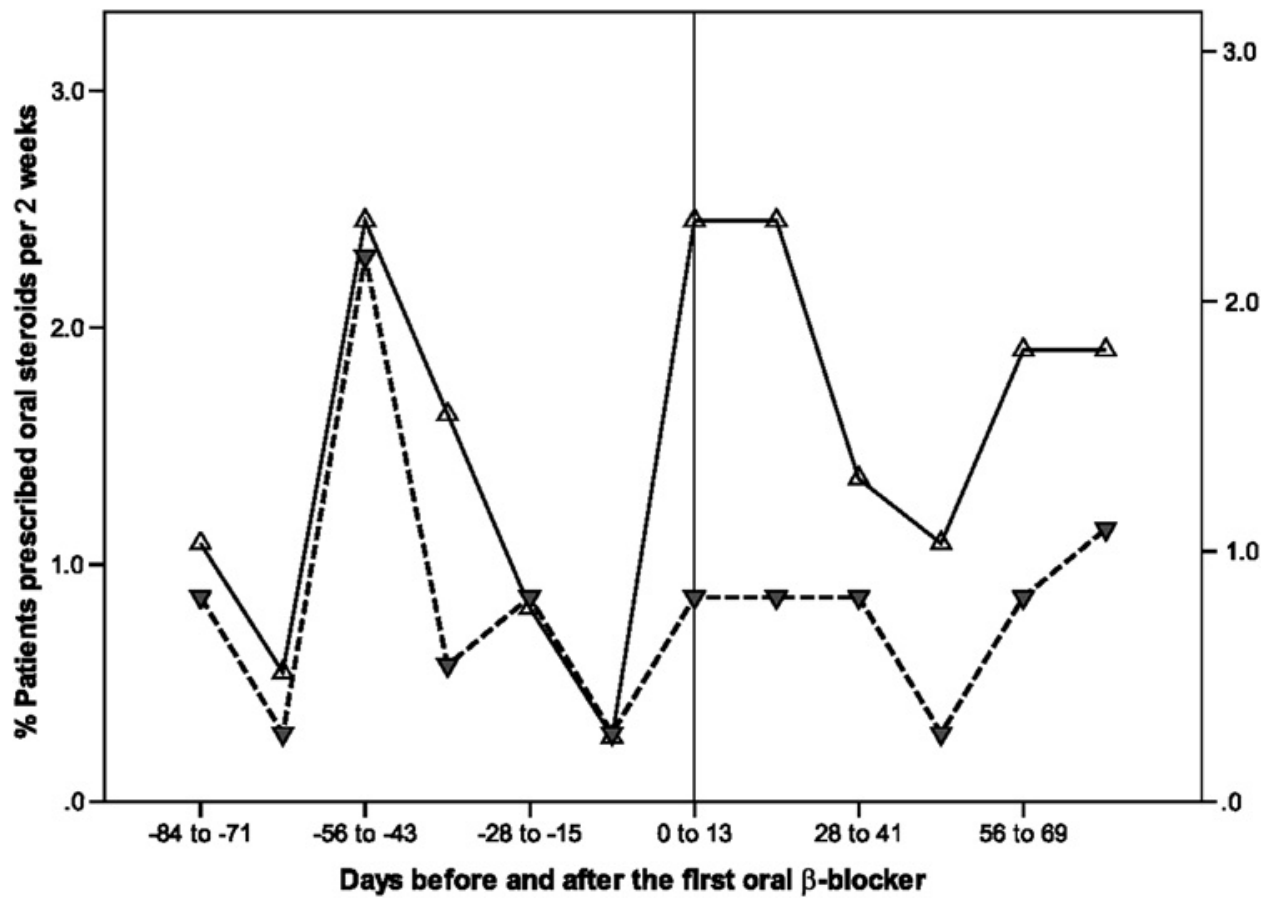


Table 5 Relative incidence of oral steroid prescribing in active asthma patients with sufficient follow-up after the new oral $\beta$-blocker prescription

\begin{tabular}{|c|c|c|c|c|c|}
\hline$\beta$-blocker & Steroid & Time period & $\begin{array}{l}\text { Patients with } \\
\text { oral steroids (\%) }\end{array}$ & $\begin{array}{l}\text { Incidence rate ratio } \\
(95 \% \mathrm{CI})\end{array}$ & p Value \\
\hline \multirow[t]{8}{*}{ Any $\beta$-blocker $(n=367)$} & \multirow[t]{4}{*}{ Rescue } & Baseline & $3.4(0.9)$ & 1.00 & \\
\hline & & $0-2$ weeks & $3.0(0.8)$ & 0.87 (0.25 to 2.99$)$ & 0.826 \\
\hline & & $2-4$ weeks & $3.0(0.8)$ & 0.89 (0.26 to 2.97$)$ & 0.845 \\
\hline & & $>4$ weeks & $2.8(0.8)$ & $0.80(0.39$ to 1.64$)$ & 0.539 \\
\hline & \multirow[t]{4}{*}{ Any } & Baseline & $4.8(1.3)$ & 1.00 & \\
\hline & & $0-2$ weeks & $9.0(2.5)$ & $1.86(0.88$ to 3.96$)$ & 0.105 \\
\hline & & 2-4 weeks & $9.0(2.5)$ & $1.85(0.87$ to 3.93$)$ & 0.111 \\
\hline & & $>4$ weeks & $5.8(1.6)$ & $1.19(0.69$ to 2.04$)$ & 0.533 \\
\hline \multirow[t]{8}{*}{ Cardioselective $(n=171)$} & \multirow[t]{4}{*}{ Rescue } & Baseline & $1.8(1.1)$ & 1.00 & \\
\hline & & $0-2$ weeks & $2.0(1.2)$ & $1.07(0.23$ to 5.03$)$ & 0.936 \\
\hline & & $2-4$ weeks & $2.0(1.2)$ & $1.12(0.25$ to 5.02$)$ & 0.881 \\
\hline & & $>4$ weeks & $1.8(1.1)$ & $0.96(0.38$ to 2.43$)$ & 0.934 \\
\hline & \multirow[t]{4}{*}{ Any } & Baseline & $2.8(1.6)$ & 1.00 & \\
\hline & & $0-2$ weeks & $7.0(4.1)$ & $2.43(0.82$ to 6.04$)$ & 0.055 \\
\hline & & $2-4$ weeks & $6.0(3.5)$ & $2.17(0.83$ to 5.46$)$ & 0.117 \\
\hline & & $>4$ weeks & $4.0(2.3)$ & 1.42 (0.71 to 2.83$)$ & 0.323 \\
\hline \multirow[t]{8}{*}{ Non-selective ( $n=196)$} & \multirow[t]{4}{*}{ Rescue } & Baseline & $1.6(0.8)$ & 1.00 & \\
\hline & & $0-2$ weeks & $1.0(0.5)$ & $0.64(0.08$ to 5.01$)$ & 0.668 \\
\hline & & $2-4$ weeks & $1.0(0.5)$ & $0.62(0.08$ to 4.91$)$ & 0.654 \\
\hline & & $>4$ weeks & $1.0(0.5)$ & $0.61(0.19$ to 1.94$)$ & 0.407 \\
\hline & \multirow[t]{4}{*}{ Any } & Baseline & $2.0(1.0)$ & 1.00 & \\
\hline & & $0-2$ weeks & $2.0(1.0)$ & $1.00(0.23$ to 4.47$)$ & 0.995 \\
\hline & & 2-4 weeks & $3.0(1.5)$ & $1.45(0.40$ to 5.21$)$ & 0.569 \\
\hline & & $>4$ weeks & $1.8(0.9)$ & $0.87(0.36$ to 2.12$)$ & 0.757 \\
\hline
\end{tabular}

Figures shown for baseline and $>4$ weeks are the mean number of patients prescribed oral steroids per 2 weeks.

Smoking status was recorded within 3 years of the date of extraction in $>98 \%$ of patients over the age of 40 . As such, we used patients over the age of 40 who had never smoked in order to reduce misclassification of COPD in our asthma population. Despite this, we were unable to exclude patients with non-smoking-related fixed airflow obstruction.

Oral $\beta$-blocker therapy is currently stated to be contraindicated in asthma due to the potential to induce acute bronchoconstriction, and the Committee for Safety on Medicines in the UK recommends that cardioselective $\beta$-blockers should only be initiated with extreme caution under specialist supervision if no alternative is available. ${ }^{18}$ However, significant numbers of patients with asthma were prescribed oral $\beta$-blocker therapy in the community, with a third of our patients receiving a nonselective $\beta$-blocker. Irrespective of $\beta$-blocker selectivity, many patients received more than one prescription. Despite these safety concerns, the number of patients with active asthma prescribed rescue steroids was remarkably low following the initial oral $\beta$-blocker, ranging from $0.5 \%$ to $1.2 \%$ of patients. Two indicators of risk were chosen for comparison, namely patients with active asthma receiving rescue or any oral steroids due to the varying indication for oral steroid prescribing. However, the differences between rescue and any oral steroid effect sizes seen for patients receiving selective $\beta$-blockers can be explained by the fact that selective $\beta$-blockers are prescribed in older patients more likely to have compelling indications for non-rescue oral steroid treatment such as polymyalgia rheumatica. Additionally, visual inspection of the oral steroid prescribing data revealed that many of these non-rescue steroid prescriptions were coprescribed on the same day as the new $\beta$-blocker, the result of which is to overexaggerate the relative incidence during the first 2 week high risk period. No statistically significant change in the number of patients requiring oral steroids related to new $\beta$ blocker prescribing was identified despite the fact that it takes up to 4 weeks for $\beta 2$-receptor function to be restored back to normal following a non-selective $\beta$-blocker, possibly due to upregulation and associated enhanced coupling of $G$ protein adenylyl cyclase. ${ }^{19} 20$ However, the CIs are relatively wide and a small increase cannot be excluded.

Given UK patterns of oral $\beta$-blocker use, it is unsurprising that the most commonly prescribed cardioselective and non-selective $\beta$-blockers were atenolol and propranolol, respectively, and it is uncertain whether patients prescribed $\beta$-blockers in this study always started with a period of dose titration. We have also demonstrated that oral $\beta$-blocker therapy was prescribed to patients with active asthma of varying severity, with approximately half of new $\beta$-blocker prescriptions being issued to patients at BTS step two or greater. This observation means that the results are unlikely to be due to confounding by indication in which only patients with stable well controlled asthma requiring little medication are exposed to $\beta$-blocker therapy and hence have less need for rescue oral steroids. All patients in the main analysis received a new prescription for oral $\beta$-blockers, and all had evidence of active asthma before commencement of the $\beta$-blocker in terms of a recent prior asthma-related prescription. With approximately half of patients on BTS step two or higher, one would expect oral $\beta$-blocker prescribing in this population to be potentially even more hazardous.

It may therefore be possible to address any small risk by appropriate dose titration upon commencement of $\beta$-blocker prescribing, and it is likely that any clinical trial looking at the potential benefits of $\beta$-blockers in asthma would start with this period of dose titration in order to identify patients whose symptoms are exacerbated at an earlier stage.

This study has several limitations. First, routine health data can be subject to missing data. However, the Primary Care Clinical Informatics Unit at the University of Aberdeen collects these data as part of the Scottish Programme for Improving 
Clinical Effectiveness (SPICE). The data that are provided are the complete historical patient record which includes all prescriptions issued by computer from general practice. As such, we have no knowledge regarding dispensed medication or patient compliance.

Secondly, the database contains anonymised data and therefore it was not possible to link to hospitalisation or mortality registers in order to identify whether any asthma patients prescribed oral $\beta$-blocker therapy received treatment in secondary care. This number, however, is likely to be small compared with the number of rescue steroids prescribed in general practice. The National Health Service (NHS) provides free access to primary care for all citizens in Scotland, and patients register with a general practice in order to access this care. All prescriptions, including those recommended by secondary care services, are issued via primary care, with the exception of short courses of medication provided at the point of hospital discharge. The Scottish Public Health Observatory provides annual statistics on asthma for Scotland. ${ }^{21}$ The incidence of hospital admissions for asthma was 11.8 per 1000 asthma patients per year using published figures on the prevalence of asthma in Scotland and the incidence of hospital admissions for the years 2005-2007, compared with an incidence of 180.2 rescue steroids per 1000 asthma patients per year from our data. Therefore, prescribing during hospital admissions for asthma is estimated to account for $\sim 6 \%$ of all prescribing.

Given the current interest in the use of $\beta$-blockers as potential therapeutic agents for patients with asthma, these initial findings appear to provide some reassurance that co-prescribing of $\beta 2$-agonists in patients with active asthma does not appear to result in a significant deterioration in asthma control requiring oral steroids in the vast majority of patients, although a small effect cannot be excluded. Further studies are now underway to evaluate the degree of airway hyper-responsiveness in such patients who have been taking $\beta$-blockers as well as their response to rescue therapy with $\beta 2$-agonists.

\section{CONCLUSION}

The annual prevalence of oral $\beta$-blocker prescribing in adult patients with asthma was $2.2 \%$, with an incidence of new $\beta$-blocker prescribing of 6.4 per 1000 asthma patients per year which included prescriptions of both cardioselective and nonselective $\beta$-blockers. Despite possible variation in dose and severity of asthma prior to the initial $\beta$-blocker, no large increase in numbers of patients with active asthma treated for severe asthma exacerbations requiring oral steroids was observed in what would be considered to be the most high risk period immediately following the new oral $\beta$-blocker prescription, although a small increase in risk cannot be excluded.

Funding The study was funded by NHS Quality Improvement Scotland. NHS Education for Scotland provided funding for the role of DRM. Neither organisation had any influence on the analysis or publication of the work.

\section{Competing interests None}

Contributions DRM had full access to all of the data in the study and takes responsibility for the integrity of the data and the accuracy of the data analysis. CJ was involved with study design, data interpretation, drafting and revision of the manuscript. BG was involved with data collection and analysis, data interpretation and revision of the manuscript. PTD was involved with data analysis and revision of the manuscript. BJL was involved with data interpretation, drafting and revision of the manuscript. All authors approved the final draft.

Provenance and peer review Not commissioned; externally peer reviewed.

\section{REFERENCES}

1. Masoli M, Fabian D, Holt S, et al; Global Initiative for Asthma (GINA) Program. The global burden of asthma: executive summary of the GINA Dissemination Committee report. Allergy 2004;59:469-78.

2. British Thoracic Society Scottish Intercollegiate Guidelines Network. British Guideline on the Management of Asthma. Thorax 2008;63(Suppl 4):iv1-121

3. Global Initiative for Asthma [Internet]. Global Strategy for Asthma Management and Prevention. http://www.ginasthma.org/ (accessed 31 Jan 2010).

4. Chowdhury BA, Dal Pan G. The FDA and safe use of long-acting beta-agonists in the treatment of asthma. N Engl J Med 2010;362:1169-71.

5. Schwartz S, Davies S, Juers JA. Life-threatening cold and exercise-induced asthma potentiated by administration of propranolol. Chest 1980;78:100-1.

6. Vatrella A, Parrella R, Pelaia G, et al. Effects of non-bronchoconstrictive doses of inhaled propranolol on airway responsiveness to methacholine. Eur J Clin Pharmacol 2001;57:99-104.

7. Callaerts-Vegh Z, Evans KL, Dudekula N, et al. Effects of acute and chronic administration of beta-adrenoceptor ligands on airway function in a murine model of asthma. Proc Natl Acad Sci USA 2004;101:4948-53.

8. Lin R, Peng H, Nguyen LP, et al. Changes in beta 2-adrenoceptor and other signaling proteins produced by chronic administration of 'beta-blockers' in a murine asthma model. Pulm Pharmacol Ther 2008;21:115-24.

9. Nguyen LP, Omoluabi 0 , Parra $S$, et al. Chronic exposure to beta-blockers attenuates inflammation and mucin content in a murine asthma model. Am J Respir Cell Mol Biol 2008;38:256-62.

10. Hanania NA, Singh S, El-Wali R, et al. The safety and effects of the beta-blocker nadolol, in mild asthma: an open-label pilot study. Pulm Pharmacol Ther 2008;21:134-41

11. Baker JG. The selectivity of $\beta$-adrenoceptor antagonists at the human $\beta 1, \beta 2$ and $\beta 3$ adrenoceptors. Br J Pharmacol 2005;144:317-22.

12. Salpeter SR, Ormiston TM, Salpeter EE. Cardioselective beta-blockers in patients with reactive airway disease: a meta-analysis. Ann Intern Med 2002;137:715-25.

13. Lipworth BJ, Williamson PA. Beta blockers for asthma: a double-edged sword. Lancet 2009;373:104-5.

14. Evans JM, Hayes JL, Lipworth BJ, et al. Potentially hazardous co-prescribing of beta-adrenoceptor antagonists and agonists in the community. Br J Gen Pract 1996;46:423-5.

15. Helms PJ, Ekins Daukes S, Taylor MW, et al. Utility of routinely acquired primary care data for paediatric disease epidemiology and pharmacoepidemiology. $\mathrm{Br} \mathrm{J}$ Clin Pharmacol 2005;59:684-90.

16. Cohn JN, Fowler MB, Bristow MR, et al. Safety and efficacy of carvedilol in severe heart failure. The U.S. Carvedilol Heart Failure Study Group. J Card Fail 1997:3:173-9.

17. Salpeter S, Ormiston T, Salpeter E. Cardioselective beta-blockers for chronic obstructive pulmonary disease. Cochrane Database Syst Rev 2005;(4):CD003566

18. Anon. Joint Formulary Committee, British National Formulary. 59th edn. London: British Medical Association and Royal Pharmaceutical Society of Great Britain, 2010.

19. Lima DR, Turner P. Beta-blocking drugs increase responsiveness to prostacyclin in hypertensive patients. Lancet 1982;2:444.

20. Lima DR, Turner P. Propranolol increases reduced beta-receptor function in severely anxious patients. Lancet 1983;2:1505.

21. Scottish Public Health Observatory. Asthma: NHS board data, 2010. http:// www.scotpho.org.uk/home/Healthwell-beinganddisease/asthma/asthma_data/ asthma nhsboarddata.asp (accessed 5 Nov 2010). 